\title{
Flutter Stability Analysis of Parked Floating Wind Turbine Blades
}

\author{
Saeid Fadaei Naeini ${ }^{* *}$, Abbas Mazidi ${ }^{2}$, Fred F. Afagh ${ }^{1}$, Robert G. Langlois ${ }^{1}$ \\ ${ }^{1}$ Mechanical and Aerospace Engineering, Carleton University, Ottawa, Canada \\ ${ }^{2}$ Mechanical Engineering, Yazd University, Yazd, Iran \\ *saeidfadaeinaeini@cmail.carleton.ca
}

\begin{abstract}
Recent developments and advancements in the technology of wind energy have led to steady growth in the size and capacity of modern horizontal-axis wind turbines (HAWTs). Continuation of this trend is expected in the future, especially in offshore applications. In this regard, floating wind turbines provide an opportunity for capturing wind energy from offshore sites. Lightweight, strong, and durable materials are used by designers for wind turbine components. The use of these materials combined with structural optimization leads to more flexible wind turbine structures. Consequently, aeroelastic behavior of wind turbines has become one of the essential aspects of their design. In the current study, flutter analysis of blades in their parked condition on floating HAWTs has been investigated. A single blade was modelled as a non-uniform Euler-Bernoulli beam in combined flapwise bending and torsion, and a discretized form of the aeroelastic governing equations was obtained using the Ritz method and Lagrange equations. To represent a realistic and practical blade, the properties of the blades on a 5 MW HAWT from the National Renewable Energy Laboratory (NREL) were accounted for in the structural equations of motion. Further, the unsteady Theodorsen's model was considered for simulating the aerodynamic load model. Discussions about the effects of base angular velocities in conjunction with airflow on the flutter speed and frequency of parked rotors are presented, and numerical results showed the significant effect of the tower base angular velocity, resulting from ocean waves, on the blade's aeroelastic stability.
\end{abstract}

Keywords- Floating wind turbine, Flutter, Non-uniform blade, Tower base angular velocity

\section{INTRODUCTION}

Horizontal-axis wind turbines (HAWTs) are complex loadcarrying structures which are subjected to non-conservative forces. In conventional land-based turbines, detection and control of the aeroelastic instabilities, such as blade flutter, have been studied by various researchers. Offshore wind turbines are more recent facilities for capturing wind energy in offshore sites. Due to a number of prevailing meteorological and geographical factors present on open waters, such as continuous high velocity winds, and large available water surfaces that are located away from population centres, thus eliminating any concerns for acoustic and visual disturbances to the public, the use of offshore HAWTs have been on the rise. Indeed, these wind turbines are the best way for capturing energy from the strong and persistent winds in offshore fields.

The trend towards lighter and more flexible blades may lead to aeroelastic instability of blades under certain circumstances, resulting in rapid destructive failure or limit-cycle oscillations of their structural components. Accordingly, the dynamics and aeroelasticity of wind turbine blades is a practical problem which has been investigated by many researchers. Although the aeroelastic and dynamic responses of blades in land-based wind turbines have been investigated rather thoroughly, analytical flutter stability analysis of blades in offshore wind turbines with realistic physical and geometrical properties has not received much attention in the literature. Hansen et al. in 2006 surveyed the state of the art in wind turbine aerodynamics and aeroelasticity [1]. The wind turbine aerodynamic modelling, structural modelling, and coupling between the aerodynamic and structural modelling parts were discussed in their work. Larsen et al. analyzed the random and nonlinear vibration of wind turbine blades by means of Monte Carlo simulation [2]. They modelled the blade as a rotating Euler-Bernoulli beam with geometrical and inertial nonlinearities. The nacelle displacement was assumed to act as a harmonic and narrow-banded excitation on the blade. Bagheri et al. used the ADAMS software package to create the dynamic nonlinear model for a floating wind turbine with a tension leg platform (TLP) and represented the dynamic response of the floating wind turbine structure to aerodynamic and hydrodynamic loads [3]. Lee et al. studied the operation and aeroelastic properties of wind turbine blades with dynamic flexible components and presented an aerodynamic model based on Modified Strip Theory [4]. Rafiee et al. investigated an aeroelastic analysis of a full-scale composite wind turbine blade by using its 3D model. They determined aerodynamic loading by using modified Blade Element Momentum theory and employed computational fluid dynamics for verification [5].

In the current study, flutter of offshore wind turbine blades in their parked condition has been investigated. This condition is not only applicable for assessing the feasibility of installing wind turbines but also as a practical way to avoid probable damage in severe environmental conditions by locking the rotors. The blade was modelled as a non-uniform bendingtorsion Euler-Bernoulli beam; and a discretized form of the 
coupled flapwise bend and twist coupled structural governing equations was obtained using the Ritz method and Lagrange equations. To accurately represent the physical and geometrical properties of the blade, for each property, a mathematical function of best fit has been developed from the series of data points obtained from a 5 MW NREL commercial wind turbine blade. These functions were used in the coupled structural and aerodynamic governing equations. The aerodynamic model was obtained based on unsteady Theodorsen's theory acting on wind turbine blade elements (BEM). The transient simulation results were compared with results obtained from the ABAQUS software package and good agreement was observed. A frequency-domain analysis was performed and discussions about the effects of roll, pitch, and platform yaw rotations on the flutter speed and frequency of parked rotors were presented and numerical results showed the significant effect of the tower platform rotations, due to ocean waves, on the blade's aeroelastic instability.

\section{PROBLEM STATEMENT}

A $5 \mathrm{MW}$ wind turbine as shown schematically in Fig. 1 is considered. The turbine blades act as cantilever beams with axially-varying structural properties. Combined flapwise bending and torsion motions are considered for this model. The wind turbine tower is assumed to be a rigid beam with three degrees of freedom of platform motion that are roll, pitch, and yaw motions.

Several coordinate systems are used to obtain the equations of motion. As shown in Fig. 1, the orthogonal inertial coordinate system XYZ is fixed at the tower root. The unit vectors of this system are $\boldsymbol{I}, \boldsymbol{J}$, and $\boldsymbol{K}$. Because the wind turbine floats on the water, it can rotate with respect to the inertial frame with angular velocity components $\Omega_{\mathrm{X}}, \Omega_{\mathrm{Y}}$, and $\Omega_{\mathrm{Z}}$ about the $\mathrm{X}, \mathrm{Y}$, and $\mathrm{Z}$ axes, respectively. Another right-handed coordinate system is the blade coordinate system, xyz, with unit vectors $\boldsymbol{i}, \boldsymbol{j}$, and $\boldsymbol{k}$ in which the $\mathrm{x}$ axis lies along the length while $\mathrm{y}$ is aligned with the flapwise direction of the un-deformed blade. The third coordinate system, $x^{\prime} y^{\prime} z^{\prime}$ with unit vectors $i^{\prime}, j^{\prime}$, and $\boldsymbol{k}^{\prime}$, is attached to the deformed blade.

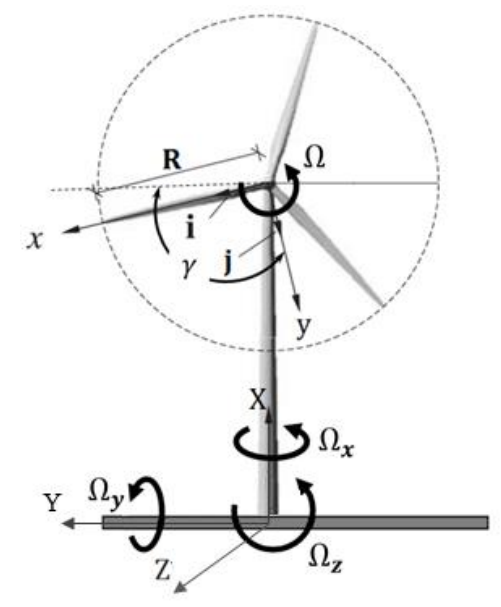

Figure 1. A schematic of wind turbine and selected coordinates.

\section{EQUATIONS OF MOTION}

Equations of motion are derived by using the Ritz method and Lagrange equations that may be expressed as:

$$
\frac{d}{d t}\left(\frac{\partial L}{\partial \dot{\boldsymbol{q}}}\right)-\frac{\partial L}{\partial \boldsymbol{q}}=\boldsymbol{Q}_{n \boldsymbol{c}}
$$

In this equation $L$ is the Lagrangian, which is defined as:

$$
L=T-U
$$

where $T$ and $U$ are the kinetic and strain energies, respectively. Also, $\boldsymbol{q}$ is the vector of generalized coordinates and $\boldsymbol{Q}_{\boldsymbol{n} \boldsymbol{c}}$ is the vector of generalized forces.

\section{WORK AND ENERGY TERMS}

The strain energy of the blade can be expressed as:

$$
U=\frac{1}{2} \int_{0}^{R} \iint_{A}\left(\sigma_{x x} \varepsilon_{x x}+\sigma_{x \eta} \varepsilon_{x \eta}+\sigma_{x \zeta} \varepsilon_{x \zeta}\right) d \eta d \zeta d x
$$

where $\eta$ and $\zeta$ are the cross-sectional local coordinates. Variables $\sigma \mathrm{ij}$ and $\varepsilon \mathrm{ij}$ are stress and strain components, respectively, which can be obtained from the displacement field [6]. By substituting these components into (3), the strain energy recasts as:

$$
\begin{aligned}
& U=\frac{1}{2} \int_{0}^{R}\left[\frac{1}{2} E A w^{\prime 4}+\frac{1}{4} \varphi^{\prime 4}\left(E I_{y^{\prime}}(x)+E I_{z^{\prime}}(x)\right)\right. \\
&+E I_{z^{\prime}}(x) \varphi^{\prime 2} w^{\prime 2}+E I_{y^{\prime}}(x) w^{\prime 2} \\
&+\frac{1}{2}\left(E I_{y^{\prime}}(x)+E I_{z^{\prime}}(x)\right) \varphi^{\prime 2} w^{\prime 2} \\
& \\
&-E A e_{A} \dot{\varphi} w^{\prime 2} w^{\prime \prime}-E B_{2} \varphi^{\prime 2} w^{\prime \prime} \\
&+\left.G J(x) \varphi^{\prime 2}\right] d x
\end{aligned}
$$

In the above equation $A$ and $E$ are the cross-sectional area and modulus of elasticity of the blade, respectively. Parameters $I_{y}$, and $I_{z}$, are the blade cross-section moment of inertia about the $y^{\prime}$ and $z^{\prime}$ axes, respectively; $J$ is the torsional rigidity constant; $e_{A}$ is the tensile axis (area centroid) offset from the elastic axis.

Blade kinetic energy can be expressed as:

$$
T=\frac{1}{2} \int_{0}^{R} \iint_{A} \rho \boldsymbol{V} \cdot \boldsymbol{V} d \eta d \zeta d x
$$

where $\rho$ is the blade density and $\boldsymbol{V}$ is the velocity vector of an arbitrary point on the turbine blade.

The vector of generalized forces $\boldsymbol{Q}_{\boldsymbol{n}}$ in (1) can be obtained by means of the Principal of Virtual Work. The virtual work of non-conservative forces acting on the blade may be expressed as:

$$
\delta W=\int_{0}^{R}(-L \delta w+M \delta \phi) d x
$$

where $L$ and $M$ are the aerodynamic lift and moment, respectively. For the calculation of the unsteady lift and moment acting on the blade, Theodorsen's theory has been adopted in 
combination with the blade element method (BEM) [7]. Also, $\delta w$ and $\delta \varphi$ are the virtual bending and torsional displacements of the blade.

\section{Physical ANd GeOMETRICAL PRoPerties OF THE BLADE}

In this research, the blade of an NREL offshore $5 \mathrm{MW}$ HAWT is considered for the aeroelastic analysis. This kind of turbine, has been of interest by many researchers in recent years. All physical and geometrical properties of the blade, such as its mass per unit length, pre-twist angle, cross-sectional area, mass moments of inertia, and chord length vary along its span. Fig. 2 shows, for example, the variation of the flap-wise inertia, edgewise inertia, and mass per unit length along the blade [9].

It can be seen from this figure that the blade properties change substantially along its span. Therefore, for an accurate modelling of the blade, its geometrical and physical properties should be considered as functions of the span-wise coordinate $x$.

\section{DisCRETIZED AEROELASTIC GOVERNING EQUATIONS}

To extract the discretized form of the blade equations of motion, the Ritz method is applied to the kinetic and strain energy terms. To this end, $w$ and $\phi$ are represented as:

$$
\begin{aligned}
& w(x, t)=\sum_{i=1}^{N} w_{i}(x) b_{i}(t) \\
& \varphi(x, t)=\sum_{i=1}^{N} \varphi_{i}(x) d_{i}(t)
\end{aligned}
$$

where $\mathrm{N}$ is the number of superimposed modes and $w_{i}(x)$ and $\varphi_{i}(x)$ are bending and torsional modes, with their respective time coefficients $b_{i}(t)$ and $d_{i}(t)$. The following family of spatial functions is used here [11]:

$$
\begin{gathered}
w_{i}(x)=\frac{\left(\frac{x}{R}\right)^{1+i}\left\{6+i^{2}\left(1-\frac{x}{R}\right)^{2}+i\left(5-6 \frac{x}{R}+\left(\frac{x}{R}\right)^{2}\right)\right\}}{i(i+1)(i+2)(i+3)} \\
\varphi_{i}(x)=\sin \left(\frac{(2 i+1) \pi x}{2 R}\right)
\end{gathered}
$$

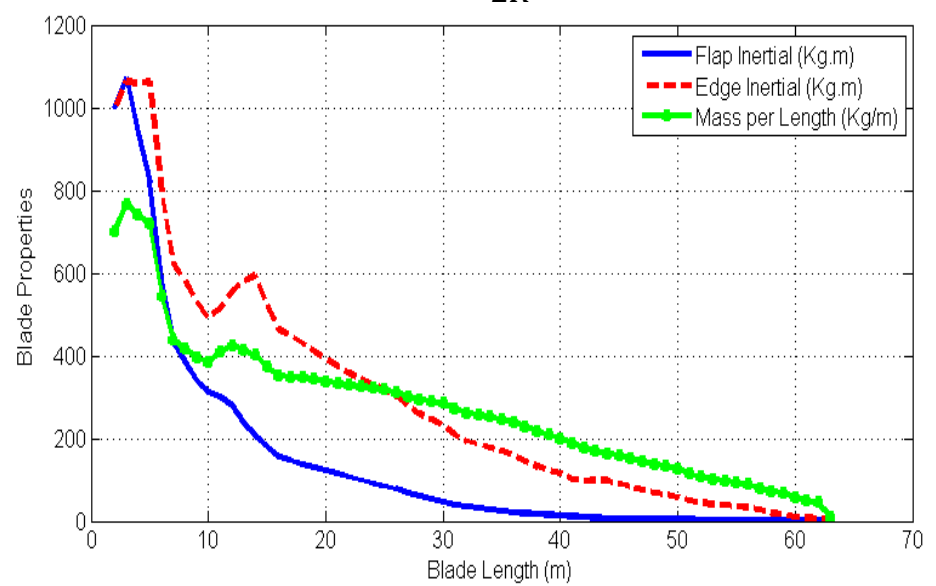

Figure 2. Variation of the flap inertia, edge inertia and mass per unit length along the blade span [9].
Substituting (7) and (8) into (4) and (5), and employing the resulting equations in the Lagrange equations, finally leads to a set of coupled ordinary differential equations in the standard form of:

$$
M \ddot{q}+C \dot{q}+K q=Q_{n c}
$$

Herein, $\boldsymbol{M}, \boldsymbol{K}$, and $\boldsymbol{Q}_{\boldsymbol{n} \boldsymbol{c}}$ denote the mass matrix, stiffness matrix and non-conservative load vector, respectively, while $\boldsymbol{q}$ is the overall vector of the generalized coordinates:

$$
\boldsymbol{q}=\left\{\boldsymbol{b}_{\boldsymbol{i}}{ }^{T} \boldsymbol{d}_{\boldsymbol{i}}^{T}\right\}^{T}
$$

\section{SOLUTION Methodology}

Due to intricate and complex coupling of generalized coordinates in aeroelastic governing equations, an exact closedform solution is formidable, but an approximate solution can be obtained based on the $\mathrm{p}-\mathrm{k}$ method [10]. According to the $\mathrm{p}-\mathrm{k}$ method, the airflow velocity that results in positive values for the real parts of the eigenvalues corresponds to the flutter velocity and correspondingly the flutter frequency.

\section{FLUTTER BOUNDARY DETECTION FOR PARKED ROTORS}

Offshore wind turbines may be affected by different weather conditions. In the case of extreme weather disturbances and severe sea states it is necessary to lock the turbine rotor. The flutter boundary, in this situation, can be detected by eigenvalue analysis. Under a locked condition, Equations (9) reduce to a set of first-order coupled ordinary differential equations as:

$$
\dot{Z}=[\boldsymbol{A}] \boldsymbol{Z}
$$

where the system matrix $[\boldsymbol{A}]$ and the state vector $\boldsymbol{Z}$, are:

$$
\begin{gathered}
{[\boldsymbol{A}]=\left[\begin{array}{cc}
{[\mathbf{0}]} & {[\boldsymbol{I}]} \\
-[\boldsymbol{M}]^{-1}[\boldsymbol{K}] & -[\boldsymbol{M}]^{-1}[\boldsymbol{C}]
\end{array}\right]} \\
\boldsymbol{Z}=\left\{\boldsymbol{q}^{T} \dot{\boldsymbol{q}}^{T}\right\}^{T}
\end{gathered}
$$

The problem is now reduced to that of determining the eigenvalues of matrix [A] at a given air speed. The flutter speed is calculated through an iterative procedure rendering zero the real part of the complex eigenvalues.

Six bending modes and six torsion modes are considered in the Ritz method to develop the discretized form of the aeroelastic governing equations. Pertinent data for the particular offshore wind turbine that have been chosen for analysis and discussion are given in Table 1. Due to the assumption of the dominant wind direction being the $\mathrm{Y}$ direction, the value of pitch rotation (in the $\mathrm{Y}$ direction) of the tower is selected to be greater than the other two roll and yaw rotation values. 
Table 1. Main parameters of the offshore wind turbine

\begin{tabular}{|l|c|}
\hline \multicolumn{1}{|c|}{ Parameter } & Value \\
\hline Yaw rotation $\left(\Omega_{X}\right)$ & $0.5 \mathrm{rad} / \mathrm{s}$ \\
\hline Pitch rotation $\left(\Omega_{Y}\right)$ & $1.0 \mathrm{rad} / \mathrm{s}$ \\
\hline Roll rotation $\left(\Omega_{Z}\right)$ & $0.5 \mathrm{rad} / \mathrm{s}$ \\
\hline Rotational velocity of the rotor $(\Omega)$ & $0 \mathrm{rad} / \mathrm{s}$ \\
\hline $\begin{array}{l}\text { Position of the angle of the blade relative to the fixed } \\
\text { coordinate system }(\gamma)\end{array}$ & $0 \mathrm{degree}$ \\
\hline \begin{tabular}{l} 
Height of the tower of the turbine $(l)$ \\
\hline
\end{tabular} & $87.6 \mathrm{~m}$ \\
\hline
\end{tabular}

\section{Structural Model VAlidation}

To validate the accuracy of the structural model developed in this investigation, results in the absence of the aerodynamic loads are compared with the corresponding results obtained using the ABAQUS software package. To this end, the NREL offshore $5 \mathrm{MW}$ wind turbine blade is modelled exactly using CATIA software. Using the geometrical data of the blade, the surface points of each blade section were obtained. The blade model was finally extracted by entering the coordinates of surface points in CATIA software. The final model of the blade is shown in Fig. 3(a). After solid modelling the blade in CATIA, in order to verify the theoretical results, the resulting model was imported into ABAQUS; and by using vibration analysis, natural frequencies of the blade were obtained. Fig. 3(b) shows the first flapwise bending mode of the blade.

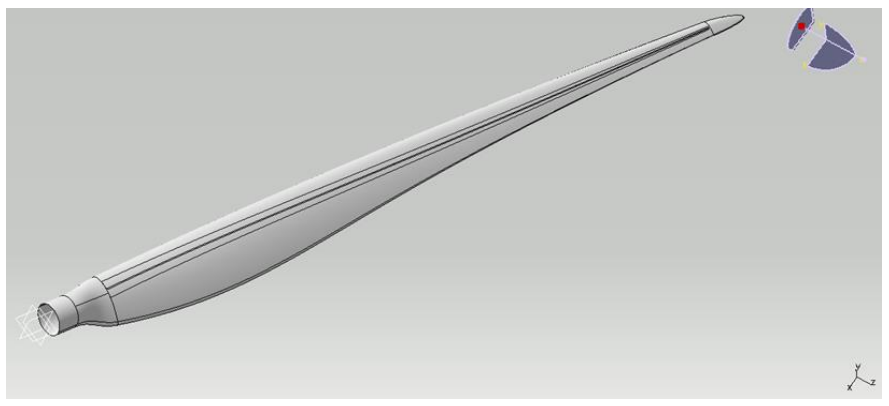

(a)

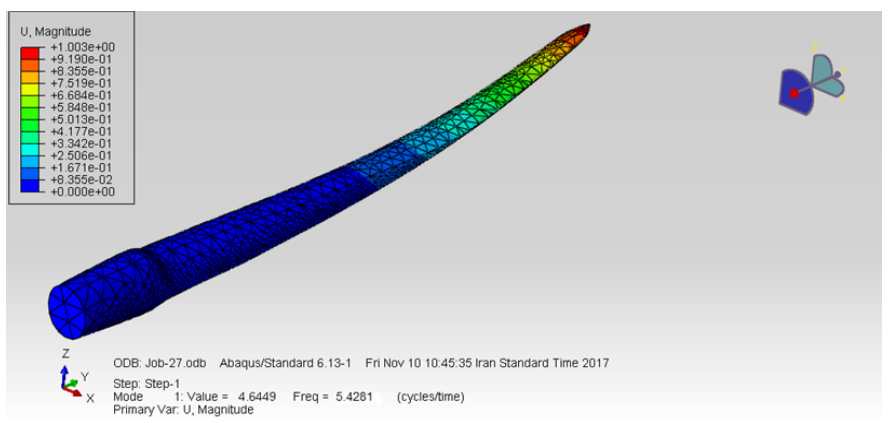

(b)

Figure 3. (a) The blade final model in CATIA, (b) The first bending mode in ABAQUS
Table 2 compares the results from our structural model with those obtained using ABAQUS. The low percentage differences between the two results demonstrates the accuracy of the present model. The small differences between the two sets of results can be attributed to the fact that in our model curve-fitted functions are used for the blade properties while in the ABAQUS analysis, the exact model was simulated.

\section{OFFSHORE WIND TURBINE WITH PARKED ROTORS}

As noted previously, in severe environmental conditions the rotors of HAWTs are usually locked to avoid any potential damage. In these conditions, the high seas can create significant rotational velocities on the tower platform of any kind of offshore wind turbine. The effects of the presence of these rotational velocities on the flutter boundary of parked turbine blades are presented here.

The effect of the yaw rotation of the tower $\Omega_{X}$ on flutter velocity and frequency of the blade is shown in Fig. 4. It can be seen from this figure that increasing $\Omega_{X}$ decreases both the flutter speed and frequency. Although $\Omega_{X}$ does not affect the flutter boundary in a significant manner, it affects the flutter frequency considerably. The effects of the pitch and roll $\Omega_{Y}$ and $\Omega_{Z}$ on flutter velocity and frequency of the turbine blade is shown in Figs. 5 and 6, respectively. Fig. 5, in which $\Omega_{X}=\Omega_{Z}=0$, indicates that increasing $\Omega_{Y}$ will decrease the flutter speed and frequency dramatically. This can be considered as an important factor in floating wind turbine design, since $\Omega_{Y}$ can destabilize the blades and lead to flutter at lower speeds.

Fig. 7 shows the effects of simultaneous presence of pitch and roll on flutter velocity and frequency of the blades. In this case $\Omega_{X}=0$ and $\Omega_{Y}$ is equal to $\Omega_{Z}$. This situation may be faced, for example, when local developing waves and fully-developed waves from a distant storm system combine, resulting in the presence of wave components from distinctly-different directions.

Table 2. Compare the results from the model with ABAQUS software solutions

\begin{tabular}{|c|c|c|c|}
\hline Frequency Mode & Current Study & ABAQUS & $\begin{array}{c}\text { Difference } \\
(\boldsymbol{\%})\end{array}$ \\
\hline $\begin{array}{c}\text { First Bending } \\
\text { Frequency (rad/s) }\end{array}$ & 5.3146 & 5.4281 & 2.136 \\
\hline $\begin{array}{c}\text { Second Bending } \\
\text { Frequency (rad/s) }\end{array}$ & 17.4057 & 17.8369 & 2.477 \\
\hline $\begin{array}{c}\text { First Twisting } \\
\text { Frequency (rad/s) }\end{array}$ & 6.7545 & 6.0084 & 11.046 \\
\hline $\begin{array}{c}\text { Second Twisting } \\
\text { Frequency (rad/s) }\end{array}$ & 31.2231 & 30.0471 & 3.766 \\
\hline
\end{tabular}
ABAQUS 


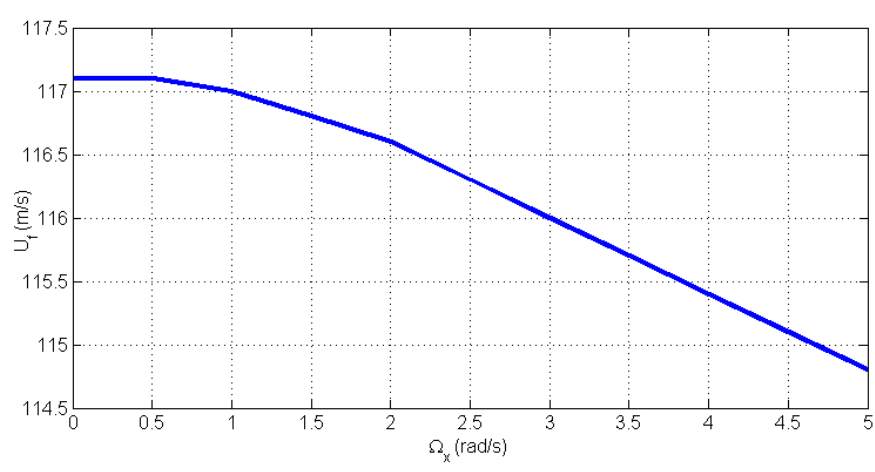

(a)

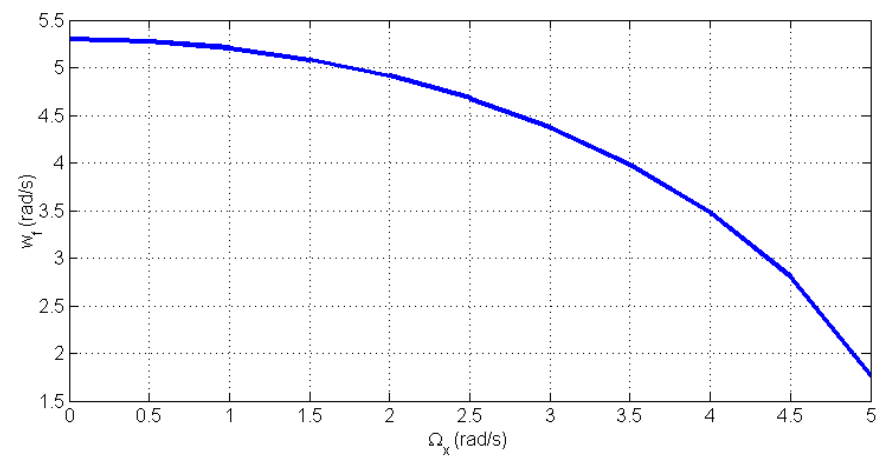

(b)

Figure 4. Effects of the yaw rotation of the tower $\Omega_{X}$ on (a) flutter velocity, $U_{f}$ and (b) flutter frequency, $w_{f}$ of parked rotor blades.

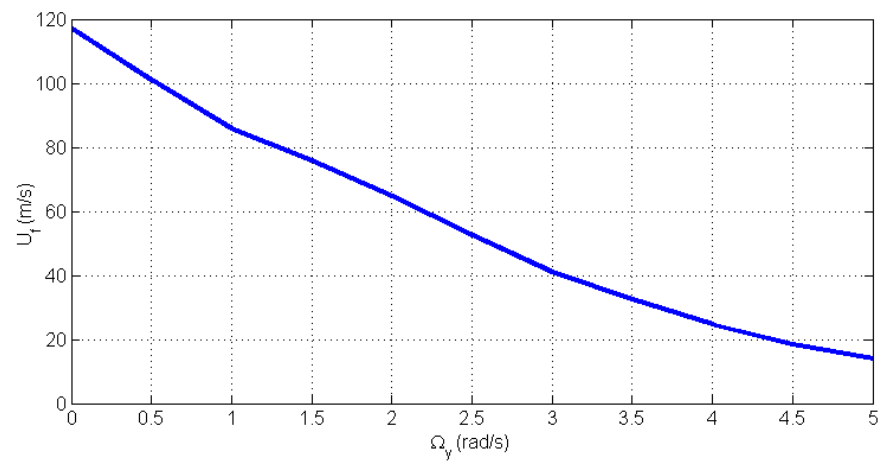

(a)

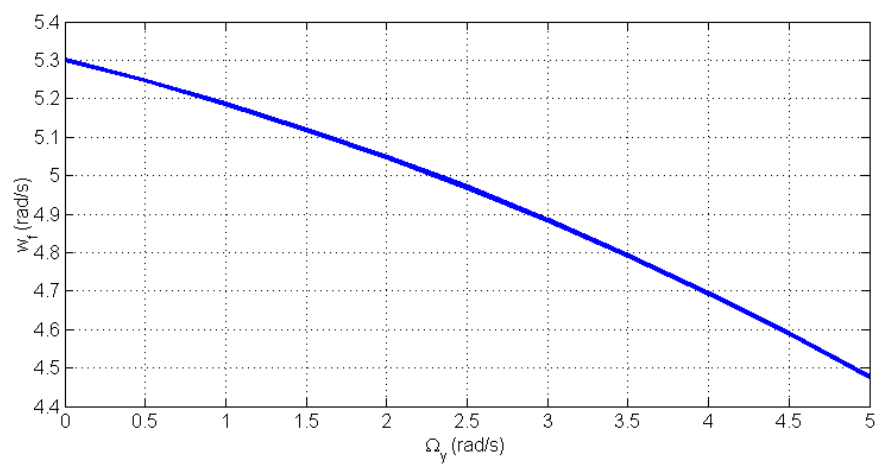

(b)

Figure 5. Effects of the pitch rotation of the tower $\Omega_{Y}$ on (a) flutter velocity, $U_{f}$ and (b) flutter frequency, $w_{f}$ of parked rotor blades.

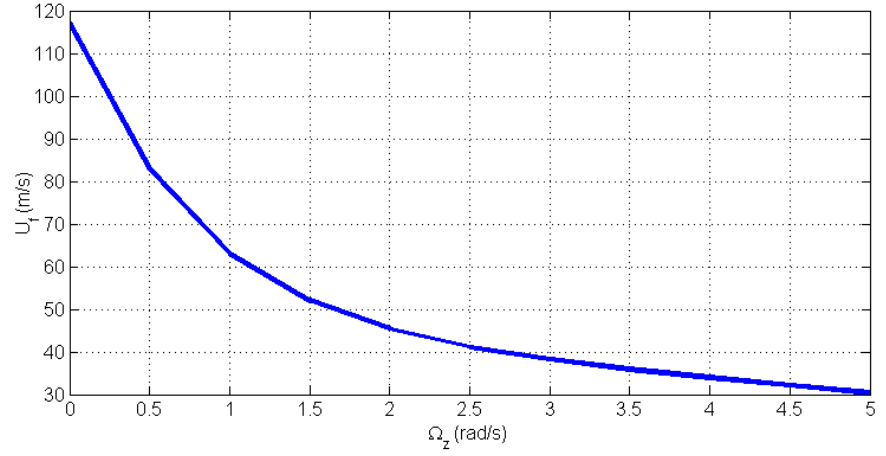

(a)

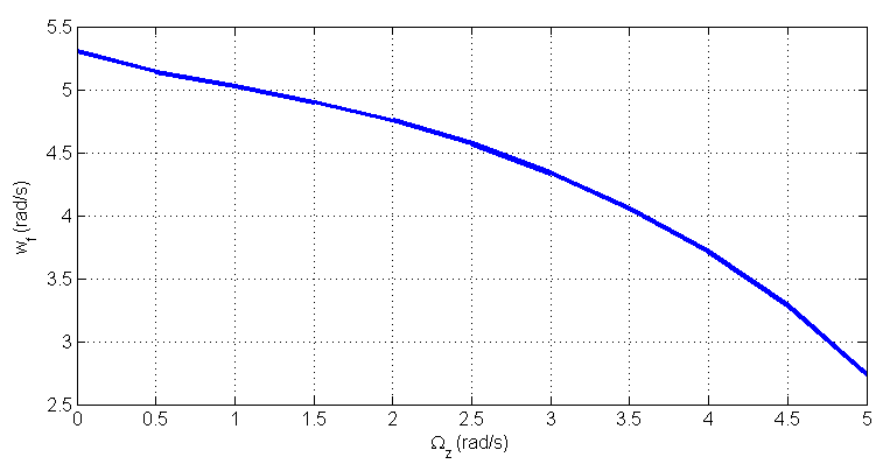

(b)

Figure 6. Effects of the roll rotation of the tower $\Omega_{z}$ on (a) flutter velocity, $U_{f}$ and (b) flutter frequency, $w_{f}$ of parked rotor blades.

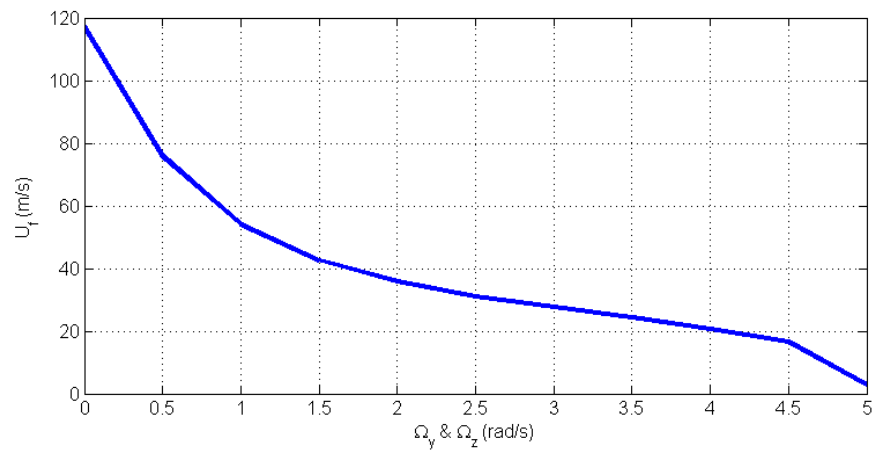

(a)

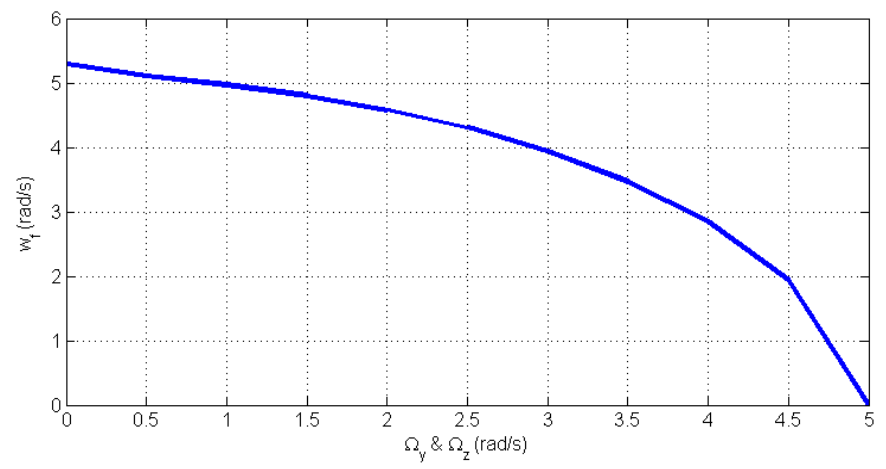

(b)

Figure 7. Effect of simultaneous presence of roll and pitch rotation of the tower $\Omega_{Y}$ and $\Omega_{Z}$ on (a) flutter velocity, $U_{f}$ and (b) flutter frequency, $w_{f}$ of parked rotor blades. 
Results indicate that an increase of wave-induced rotational velocities in the tower platform can induce a lower flutter speed and frequency. This means that the platform rotations decrease the aeroelastic stability region of the turbine blades. For large values of these angular velocities, the diagram may coincide with the zero-velocity line which means that the base angular velocity leads to instability even in the absence of the air flow. Table 3 compares and summarizes results of the flutter analysis of the wind turbine blades in the parked rotor condition.

\section{CONCLUSION}

Parametric flutter analysis of the blades of an offshore HAWT on any kind of platform that is subjected to three rotations, is considered in this study. The blade is modelled as a non-uniform bending-torsion flexible beam and its geometric and physical properties are extracted from a NREL 5 MW wind turbine blade. Unsteady aerodynamic lift and moment are obtained based on unsteady Theodorsen's theory and included in the aeroelastic governing equations. A parametric study of platform rotations on the flutter speed and frequency of parked rotors is presented. Results show that the platform rotation has a detrimental effect on the flutter and restricts the blade's dynamic stability region. Although, increasing the rotational velocity of the platform always seems to lower the flutter speed and frequency, simultaneous generation of roll and pitch, $\Omega_{Y}$ and $\Omega_{Z}$ of the tower platform has the most significant effect on limiting the stability region of turbine blades.

Table 3. The summary of the aeroelastic results for wind turbines with parked rotors

\begin{tabular}{|c|c|c|}
\hline Rotation velocity of tower & $\begin{array}{c}\text { Flutter } \\
\text { Velocity } \\
(\mathbf{m} / \mathbf{s})\end{array}$ & $\begin{array}{c}\text { Flutter } \\
\text { Frequency } \\
(\mathbf{r a d} / \mathbf{s})\end{array}$ \\
\hline$\Omega_{X}=1\left(\frac{\mathrm{rad}}{\mathrm{s}}\right), \Omega_{Y}=\Omega_{Z}=0$ & 117 & 5.206 \\
\hline$\Omega_{Y}=1\left(\frac{\mathrm{rad}}{\mathrm{s}}\right), \Omega_{X}=\Omega_{Z}=0$ & 94.9 & 5.1854 \\
\hline$\Omega_{Z}=1\left(\frac{\mathrm{rad}}{\mathrm{s}}\right), \Omega_{X}=\Omega_{Y}=0$ & 63.1 & 5.0234 \\
\hline$\Omega_{Y}=\Omega_{Z}=1\left(\frac{\mathrm{rad}}{\mathrm{s}}\right), \Omega_{X}=0$ & 54.2 & 4.9652 \\
\hline
\end{tabular}

[1] M. O. L. Hansen, J. N. Sørensen, S. Voutsinas, N. Sørensen, H. Aa. Madsen, "State of the art in wind turbine aerodynamics and aeroelasticity," Progress in Aerospace Sciences, Vol. 42, No. 4, pp. 285 300, 2006.

[2] J. W. Larsen, S. R. K. Nielsen, R. Iwankiewicz, "Non-linear stochastic stability analysis of wind turbine wings by Monte Carlo simulation," Probabilisitic Engineering Mechanics, Vol. 22, No. 2, pp. 181-193, 2007.

[3] M. Baghaei, H. Shahverdi, S. M. Hasheminejad, "Aero-Hydro-Elastic modeling of a floating wind turbine," Journal of Modeling in Engineering, Vol. 10, No. 30, pp. 1-17, 2012, In Persian.

[4] J. W. Lee, J. S. Lee, J. H. Han, H. K. Shin, "Aeroelastic analysis of wind turbine blades based on modified strip theory," Journal of Wind Engineering and Industrial Aerodynamics, Vol. 110, pp. 62-69, 2012.

[5] R. Rafiee, M. Tahani, and M. Moradi, "Simulation of aeroelastic behavior in a composite wind turbine blade," Journal of Wind Engineering and Industrial Aerodynamics, Vol. 151, pp. 60-69, 2016.

[6] D. Hodges, E. Dowell, "Nonlinear equations of motion for the elastic bending and torsion of twisted non-uniform rotor blades," NASA TN D7818, 1974.

[7] T. Wang, "A brief review of wind turbine aerodynamics," Theoretical \& applied mechanics letters, Vol. 2, pp. 062001, 2012.

[8] M. O. L. Hansen and H. A. Madsen, "Review Paper on Wind Turbine Aerodynamics," Journal of Fluid Engineering, Vol. 133, pp. 114001114001-12, 2011.

[9] J. M. Jonkman, S. Butterfield, W. Musial and G. Scott, "Definition of a 5MW reference wind turbine for offshore system development," National Renewable Energy Laboratory (NREL), 2009.

[10] D. H. Hodges, G. A. Pierce, Introduction to Structural Dynamics and Aeroelasticity, Cambridge University Press, Cambridge, 2002. 